\title{
Industrial Risk Management: Modeling From the Explosion of the 19/01/04 Complex of Liquefied Natural Gas, Skikda (GL1 / K)
}

\author{
Hanya KHERCHI MEDJDEN, Khadidja SADI \\ ENSSEA, Algiers, Algeria
}

\begin{abstract}
After several incidents or accidents, the most serious case being the one who struck the complex Skikda liquefied natural gas (GL1 / K) on January 19, 2004, the group Sonatrach sensitive to the incident has taken further steps along the lines of prevention safe knowing that the business risk is an integral part of the business industry and it is about health, safety, and environmental protection. These factors will be taken into account in the process of management and decision making at all levels. This study tries to find the causal factors of the explosion of 19 January 2004 (GL1 / K) and to develop a fault tree and assess the risks arising from these factors, why our research is based on interviews: at first, with an industrial safety engineer (Health, Safety, and Environment (HSE) Department, General Direction of Sonatrach), an executive director of insurance, a department head of insurance, an insurance consultant, a department head of downstream activity and two financial executives; secondly, a poll at the general direction with insurance adjusters and engineers in industrial safety; and finally a report may visit the complex which has been made (the report) 15 days before the explosion. The cause-effect diagram is used which is a cause-effect method both upwards (search for causes of failure) and down (search for consequences of failure) that can not only identify risks system and the detailed analysis, but also can describe the form of a single graph, both the normal operation of a system. The default trees developed show that all the risks assessed are located in areas: acceptable, undesirable, and intolerable, which requires the development of an action plan providing control measures at all sensitive points.
\end{abstract}

Keywords: industrial risk, probability of default, failure tree

\section{Introduction}

The danger is defined as a situation which, in itself, a power to cause damage to people and property, otherwise the danger is the situation or condition that threatens the physical integrity of persons. There is a danger or nuisance when a material, a product, a procedure, and an organization are able to cause immediate damage or delayed.

There are many definitions of risk. According to the definition found in Webster's, it is written: "Danger

Hanya KHERCHI MEDJDEN, Doctor in Statistics and Applied Economics, Lecturer, High School of Statistics and Applied Economics, ENSSEA.

Khadidja SADI, Doctor in Statistics and Applied Economics, Lecturer, High School of Statistics and Applied Economics, ENSSEA.

Correspondence concerning this article should be addressed to Hanya KHERCHI MEDJDEN, 32 rue Ahmed Boumazouza El Madania Alger Algeria. E-mail: kherchi.hanya@enssea.dz. 
any more or less predictable", and it is written in the Littre "Too bad more or less any foreseeable event against the occurrence of which it is ensured, the made to expose them to danger, in the hope of getting a perk". According to the statistical risk, it is considered as the combination of issues subject to a hazard, that is to say, the confrontation a probability of an event by the vulnerability of the wider environment. So this paper notes:

(1) The hazard is the likelihood or probability of the occurrence of a phenomenon or event;

(2) The issue or vulnerability—-three types of issues can be distinguished:

- The human issues: It is individuals directly or indirectly exposed to the consequences of the accident. They can be found in a public place, at home, at their place of work, etc.. The risk can range from minor injuries to death. The type of accident affects the type of injury;

- Economic issues: A major industrial accident may alter the economic tool of an area. Businesses, roads, or railway adjacent to the site of the accident may be destroyed or severely damaged. In this case, the economic consequences can be disastrous;

- Environmental issues: A major industrial accident can have significant impacts on ecosystems. You can watch the destruction of fauna and flora, but the consequences of an accident may also have an impact on health (for example, pollution of groundwater).

All human activity, even trivial, may cause undesirable consequences: excess food and beverages (cancers, cardiovascular disease), smoking and breathing polluted air (cancers, cardiovascular diseases), housework (falls), and dangerous sports (injury, death).

Zero risk which does not exist is a risk that can be reduced, without ever being canceled. For example, a minimal risk, because the probability $(P)$ of the event in question is very small, but the consequences would be incalculable, is the impact of the earth with an asteroid large enough to cause this that it is called a nuclear winter.

\section{Risk Perception and Evaluation}

It should be noted that the counterparty risk is always a benefit, it is the case of voluntary risk that is to say, the selected risks, to which the salary will be adjusted to the dangers incurred, by the example as the case of journalists sent to cover events in areas affected by military operations. This is also the case of involuntary risks which is to say the risk of damage, but in this case, who withdraws the benefit is not necessarily the one liable as areas invaded by pollution due to cement plants, the key risk here and the surrounding population are benefited employees of the plant.

\section{Actual Risk, Perceived Risk}

The real risk is the risk assessed by data already known (risk $=$ hazard $\times$ issues).

Perceived risk is the risk as perceived by the public in general little able to estimate the importance of lack of information or technical knowledge. A simple example is the natural apprehension that there may be riding in a plane.

\section{Major Risk}

The major risk is called when the phenomenon is widespread and vulnerabilities. Risk is also called major when during an event of natural or technological monitoring impact on people, property, and the environment, the public may lose confidence in the political and economic powers.

Generally the major risk is characterized by many victims, a significant cost of damage, impacts on the environment and the economy. 


\section{Industrial Risk}

Industrial risk is a major risk. The term "business risk" is the likelihood of a specific effect occurring within a specified period or in specified circumstances, due to a major accident event related to loss of control of an industrial activity. These effects may have implications for site personnel, surrounding communities, buildings, and the environment.

On the other way, industrial risk is an accidental event such as a gas emission, fire, or explosion of major character, which occurs on an industrial site and causing immediate and serious consequences for neighboring populations, property, or environment. All activities requiring large amounts of energy or products are concerned, that in case of malfunction, the emanation of these energies or products have consequences beyond the confines of the factory. Depending on the mode of action on human and relevant products, industrial risks are divided into three categories:

- Risk of fire or thermal hazard;

- Risk of explosion;

- Risk toxic.

\section{Industrial Risk Assessment}

There are several methods for assessing industrial risk among them: The analysis of failure modes, effects, and criticality of their Failure Mode and Effects Analysis (FMEA) is an analytical approach and probabilistic down which aims to analyze in a systematic and preventive system failures or a technical device whose consequences can affect its reliability and maintainability.

It uses two different and complementary analyzes:

- A qualitative analysis of failure modes, their causes and their effects;

- A quantitative analysis of the severity of consequences and the likelihood of failure modes and their impact on the reliability and maintainability of the system considered.

The FMEA, general conduct in the design phase of the system or sub-system can also be used during operation to trigger remedial actions to perform.

It can be applied both to a product or a modification (FMEA-product), as a process or method of production, manufacturing, quality control (process-FMEA) or only means of production (FMEA Middle-production).

The preliminary risk analysis (PRA). The PRA is an approach to top-down analysis and deterministic designed by the United States (U.S.) Army in the 1960s. It aims to highlight the main risks likely to be encountered in the design of new systems.

This method generally carried from the beginning of the system design at a global level, however, can be made throughout the design, even when operating studied in order to make updates or perform further analysis.

It can quickly highlight the main risk situations and without wanting to go into too much detail, a system can serve as the basis for the subsequent production of more detailed analyzes.

The cause-effect diagram. The diagram or graph is a cause-effect method both upwards (search for causes of failure) and down (search for consequences of failure) that can not only identify risks system and the detailed analysis, but also can describe the form of a single graph, both the normal operation of a system.

This method is very useful for identifying when the design or operation, the risks of systems consist of a sequence of actions relatively predictable. 
It is thus a valuable aid for the identification of scenarios constituting the predominant risks.

Markov chains. Markov chains are stochastic, which are tools modeling aimed to analyze and assess the reliability or availability of a system as a whole (the graphs used then being significantly different).

They describe chains of events analytically and graphically the behavior of dynamic systems (transition from one state to another state) and calculate the characteristics and conditions of the cruising speed when is reached.

The Monte-Carlo. The Monte-Carlo (stochastic) is the technique of simulation random universe that leads to very detailed analyzes of complex systems.

It can be used not only to simulate the behavior (operation and malfunction) systems subject to various risks and for which it is difficult to obtain sufficiently reliable information, but can also be used for project scheduling problems to perform quantitative analysis of certain risk components, namely, the impact of the variability of the duration or cost of project tasks.

Performing a simulation by the Monte-Carlo method, on the one hand, requires well studied model of the system (in the form of a graph, a tree, and a network etc.) and on the other hand, is based on the drawing of random numbers, that is to say random number following a certain probability distribution.

It generally requires the use of a simulation tool with a random number generator and a battery of probability laws which can cover most situations.

Petri nets. Petri nets (stochastic) are a specific application of the Monte-Carlo method, invented in 1962 to describe the system behavior automated manufacturing, they are now used in many areas to improve the dependability of complex systems, they used to model and simulate dynamically (taking into account the time factor) the evaluation of a system to represent graphs by changing the various successive states of the system studied.

\section{Hazard Identification of Complex Gl1 / K}

\section{Fire and Explosion}

Complex GL1 / K has two distinct major areas:

- The first area is dedicated to the process units $10,20,30$, and 40 as well as utility and storage;

- The second area relates to Units five and six, and the associated storage.

The distance between these two areas is about 700 meters and it can be considered that the risk of destruction from one zone to another is relatively low. Regarding the distance between the process units, the average is 24 meters. This distance is to consider, in the event of a major incident on train liquefaction as likely to cause serious damage to nearby facilities.

\section{Risks Surrounding}

On the east side of units five and six, there are complex petrochemical facilities of national petrochemical company. The risk of explosion due to the storage of ethylene and ethane is not excluded. In addition, he noted the absence of the nearby airport complex.

\section{Environment}

The enviroment which includes the following parts:

- Climates: The average summer temperatures are between $28^{\circ} \mathrm{C}$ and $32{ }^{\circ} \mathrm{C}$. In winter they are between $10^{\circ} \mathrm{C}$ and $0^{\circ} \mathrm{C}$. The average humidity is $54 \%$ in winter and $76 \%$ in summer. 
- Precipitation: The average rainfall is about $400 \mathrm{~mm}$ of water per year especially during the winter months;

- Wind: The predominance of winds is North-West/North-East. Wind speed may exceed $50 \mathrm{~km} / \mathrm{h}$;

- Earthquake: The region is considered as an active seismic zone;

- Flooding: It should be noted that there is no river or near to river, that an accident in the complex could cause a risk of flooding.

\section{Evaluation of Explosion of 19 January 2004 (GL1 / K)}

On 19 January, 2004, a strong explosion occurred at 18:40 at the complex natural gas liquefaction Skikda (GL1 / K).

The Units 40, 30, 20, and 10 of the six units of liquefaction, that include GL1 / K complex, were heavily damaged and subjected to an intense fire.

The Power Plant SONELGAZ terraced Complex LNG was triggered as a result of the shock wave of the explosion.

It is unfortunate that this incident was the cause of 23 deaths and 74 wounded evacuated to the hospital in Skikda which 42 have left after receiving the necessary care and five have been sent to hospital Annaba.

This study tries to find the causal factors of the explosion of 19 January 2004 (GL1/K) to develop a fault tree and assess the risks arising from these factors, why our research is based on interviews with:

(1) Interviews with:

- An industrial safety engineer (HSE Department, General Direction of Sonatrach);

- An executive director of insurance (Department of Insurance, Branch Sonatrach);

- A department head of insurance (Department of Insurance, Branch Sonatrach);

- Insurance consultant (Department of Insurance, Branch Sonatrach);

- Department head of downstream activity (Department downstream Branch Sonatrach);

- Two financial executives (Department of Insurance, Branch Sonatrach).

(2) A poll is at the general direction with insurance adjusters and engineers in industrial safety;

(3) A report may visit the complex, which has been made (the report) fifteen days before the explosion.

\section{The Tree of Default:}

Two random events occur exclusively or inclusively. So the logical operator "OR" indicates that the event occurs independently if any events are based and the logical operator "AND" indicates that the event occurs only if the basic events exist simultaneously.

The disaster of 19 January 2004 was due to two assumptions:

Hypothesis 1: A main problem-a fire or explosion.

Fire: The main causes of the fire are due to faulty heating appliances, careless smokers, wiring damage, and undetermined causes;

Explosions: either a type scenario Unconfined Vapor Cloud Explosions (UVCE), or type scenario Boiling Liquid Expanding Vapor Explosion (BLEVE):

(1) UVCE: It is an ignition source and a gas leak (simultaneously).

- Ignition source: This is defective heating equipment or careless smokers or wiring damaged or undetermined causes;

- Gas leak: poor reservoir quality problem or maintenance of the equipment or poor quality equipment or an 
appliance or amortized or depreciated pipe maintenance problem of a pipe.

(2) BLEVE: It is a human problem, or an organizational problem, or a technical problem.

The human problem is being lack of training or lack of vigilance or premeditated destruction;

- Organizational problem: either emergency procedure or system of work or work permit or updated documentation or procedure or work instruction or wrong interpretation of terms of internal organization;

- Technical problem: It is a device problem or an issue or a problem tank boiler or pipe problem;

- Problem of device: maintenance, quality, overload device, or amortized;

- Tank problem: quality, overload, or environment;

- Boiler problem: overloading, maintenance, or leaking steam;

- Pipe problem: maintenance is depreciated.

Hypothesis 2: The problem and the response team firefighters.

This is a problem response team or at firefighters.

- Response team: lack of training, insufficient equipment, experience, or team died;

- Firefighters: lack of training, not enough equipment, or shortage.

\section{Probability of Basic Events}

The estimated probabilities of basic events can be calculated from:

Databases that was nonexistent at Sonatrach;

Tests whenever possible, however it was impossible because regulations do not allow Sonatrach.

Expert judgment: In this step the company organizes a council of all experts and engineers of all levels, who believes his own probabilities.

Finally the following assumptions are set:

(1) These probabilities are arbitrary;

(2) $n=43$ (since there are 43 basic events);

(3) The sum of probabilities equal to $1: \sum_{1}^{43} P_{i}=1$;

(4) Probability > 0023 : high probability;

Probability $<0023$ : low probability.

where:

$0.0023=1 / 43$.

Necessary formulas for estimating probabilities of intermediate events and disasters (dreaded) are:

BLEVE:

To calculate the probability of the event through BLEVE, it must calculate the probabilities of intermediate events that make up the BLEVE namely:

- Human is :

Human (lack of training) OR (lack of alertness) OR (premeditated destruction).

$P($ Human $)=P($ lack of training $)+P($ Complacency $)+P($ premeditated Destruction $)$.

- Organizational is:

Organizational Plan (internal organization) OR (work system) OR (Mal interpretation set) OR (How to work) OR (Updated documentation) OR (Emergency Procedure) OR (Work Permit).

$P($ Organizational $)=P($ Plan internal organization $)+P($ work system $)+P($ Mal interpretation set $)+P$ 
(Procedure for work $)+P$ (Updated documentation $)+P$ (Procedure emergency $)+P$ (Work Permit)

- Technical is:

(Camera) OR (Reservoir) OR (boiler) OR (Pipe)

$P($ Technique $)=P($ Camera $)+P($ tank $)+P($ boiler $)+P($ Pipe $)$

BLEVE $=($ Human $)$ OR (Organizational) OR (Technical)

\section{Results}

\section{BLEVE:}

The probability that the cause of a BLEVE scenario is:

$P$ (human problem) $=0.023$;

$P($ Organizational $)=0.133$;

$P($ Technical $)=0.302$, which is the highest probability;

$P($ BLEVE $)=0.023+0.133+0.302=0.458$.

And $P($ technical problem $)=P($ device problem $)+P($ reservoir problem $)+P($ boiler problem $)+P($ pipe problem):

$P($ device problem $)=0.14$;

$P($ reservoir problem $)=0.027$;

$P$ (boiler problem) $=0.03$;

$P$ (pipe problem) $=0.1$.

So a technical problem is most likely that it is the cause of a BLEVE scenario, and a device is more likely to cause a technical problem.

\section{UVCE:}

The operator UVCE logic is “AND” so the two probabilities causing the problem cannot be compared:

$P($ Ignition source $)=0.11300$;

$P($ Gas leak $)=0.16500$;

$P($ UVCE $)=0.11300 \times 0.16500=0.018605$.

- E explosion:

It is noted that the probability of a BLEVE $(0.458)$ is greater than that of UVCE $(0.018605)$, and then a BLEVE scenario is most likely to explode. But that UVCE probability is not zero cannot be eliminated.

- Fire:

The probability of fire is (0.06). If this is compared with the probability of explosion (0.476645), then it can be said that the phenomenon is a blast, but as the probability of fire is not zero, there is always a possibility that the phenomenon is a fire.

- Response team and firefighters:

The probability of response team is $(0.0907)$ and firefighters are $(0.107)$, then the problem was probably a firefighter's problem response team, without eliminating the intervention team.

\section{Disaster of January 19, 2004 Events}

It is noted that the logical operator is "AND”, so the two cases cannot be compared, but the probability is equal to (0.11), that is to say, the possibility, that the causes of the disaster are those which have been found in our research, is $(11 / 100)$. 
The matrix evaluation risks:

Greater likelihood of intervening events is the "Technology" (BLEVE). To construct the intervals is divided by five (there are five levels of probabilities) (see Table 1).

Table1

Intervals of Probabilities for Risk Assessment

\begin{tabular}{ll}
\hline Intervals of probabilities & Risk assessment \\
\hline$[0$ to 0.0604$]$ & Extremely unlikely \\
{$[0.0604$ to 0.1208$]$} & Unlikely \\
{$[0.1208$ to 0.1812$]$} & Possible \\
{$[0.1812$ to 0.2416$]$} & Probable \\
{$[0.2416$ to 0.302$]$} & Inevitable \\
\hline
\end{tabular}

There are four types of gravity (see Table 2). The gravity depends on the damage caused:

- Slight;

- Moderate;

- Grave;

- Disastrous.

$$
\text { Risk }=\text { Probability } \times \text { gravity }
$$

Table 2

Matrix of Risk Evaluation

\begin{tabular}{|c|c|c|c|c|c|}
\hline Probability & Gravity & Slate & Moderate & Grave & Disastrous \\
\hline Inevitable & & 5 & 10 & 15 & 20 \\
\hline Probable & & 4 & 8 & 12 & 16 \\
\hline Possible & & 3 & 6 & 9 & 12 \\
\hline Unlikely & & 2 & 4 & 6 & 8 \\
\hline Extremely unlikely & & 1 & 2 & 3 & 4 \\
\hline
\end{tabular}

We can now evaluate the risks by source of danger as indicated in Table 3.

Table 3

Risk Evaluation of the Explosion January 19, 2004

\begin{tabular}{|c|c|c|c|c|c|}
\hline \multirow{2}{*}{$\begin{array}{l}\text { Sources of danger } \\
\text { Lack of training-Lack of vigilance-Premeditated destruction }\end{array}$} & \multirow{2}{*}{$\begin{array}{l}\text { Consequence } \\
\text { Human (BLEVE) }\end{array}$} & \multicolumn{2}{|c|}{ Probability } & \multirow{2}{*}{$\begin{array}{l}\text { Gravity } \\
4\end{array}$} & \multirow{2}{*}{$\frac{\text { Risk }}{4}$} \\
\hline & & 0.023 & 1 & & \\
\hline $\begin{array}{l}\text { Internal organizational plan-Work system-Wrong interpretation of set point- } \\
\text { Working procedure-Last updated from the documentation-Emergency } \\
\text { procedure-Work permit }\end{array}$ & $\begin{array}{l}\text { Organizational } \\
\text { (BLEVE) }\end{array}$ & 0.133 & 2 & 3 & 9 \\
\hline $\begin{array}{l}\text { Maintenance unit-Quality appliance-Overload device-Unit cushioning- } \\
\text { Quality tank-Environment-Overload tank-Overload boiler-Leak steam- } \\
\text { Maintenance boiler-Maintenance Pipe-Pipe cushioning }\end{array}$ & $\begin{array}{l}\text { Technique } \\
\text { (BLEVE) }\end{array}$ & 0.302 & 5 & 4 & 20 \\
\hline $\begin{array}{l}\text { Devices of heating systems-Undetermined causes-carelessness of smokers- } \\
\text { Electrical installation }\end{array}$ & $\begin{array}{l}\text { Source ignition } \\
\text { (UVCE) }\end{array}$ & 0.113 & 2 & 4 & 8 \\
\hline $\begin{array}{l}\text { Quality of the reservoir-Maintenance of the machine-Quality of device-Unit } \\
\text { depreciated-Pipe amortized-Maintenance pipe }\end{array}$ & $\begin{array}{l}\text { Gas leak } \\
\text { (UVCE) }\end{array}$ & 0.165 & 3 & 4 & 12 \\
\hline $\begin{array}{l}\text { Devices of heating systems-Carelessness of smokers-Undetermined causes- } \\
\text { Electrical installation }\end{array}$ & Fire & 0.06 & 1 & 3 & 3 \\
\hline Not enough material-Lack of experience-Team died-Lack of training & Response team & 0.031 & 1 & 2 & 3 \\
\hline Lack of training-Not enough material-Lack of experience & Firefighters & 0.085 & 2 & 2 & 4 \\
\hline
\end{tabular}




\section{Conclusions}

This paper discusses the risk assessment of a complex gas activity, where the acceptable risk can develop instantly an intolerable risk. An amount for each area of risk cannot be given. The disaster has cost a total loss of 452 million U.S. dollars (32,544 million dinars Algeria).

For sources of danger "Human" (lack of training, lack of vigilance, premeditated destruction) that result in a BLEVE scenario, the risk equals four representing an acceptable risk. For sources of danger "Organizational" which resulted in a BLEVE scenario, the risk equals nine representing a risk adverse. Regarding the sources of danger "Technology" (BLEVE consequence), the risk is 20, which represents an intolerable risk. Regarding the sources of danger "Ignition source", the risk is equal to eight, so risks adverse. For sources of danger "gas leak" (result UVCE), the risk is equal to 12, people are in the area of undesirable risk. For sources of danger which have resulted in a fire, the risk is equal to three which are positioned in the acceptable risk. For sources of danger have a problem with team intervention, the risk is equal to eight (undesirable risk). For sources of danger having a problem with firefighters, the risk is equal to six (acceptable).

It is noted that all the risks assessed are located in areas: acceptable, undesirable, intolerable, which requires the development of an action plan providing control measures at all sensitive points.

\section{References}

Courtot, H. (1998). La gestion des risques dans les projets. Retrieved from http://www.economica.net/

European Comity commission. (2003a). Directive 1999/92/CE du Parlement Européen et du Conseil concernant les prescriptions minimales visant à améliorer la protection en matière de sécurité et de santé des travailleurs susceptibles d'être exposés au risque d'atmosphères explosives (pp. 0057-0064). Journal officiel No. L 023, Bruxelles.

European Comity commission. (2003b). Guide de bonne pratique à caractère non Contraignant. Bruxelles Commission Européenne DG Emploi, Affaires Sociales et égalité des Chances Unité D4.

French Institute of Environnement. (2005). La perception sociale des risques naturels. Données d l'environnement, No. 99, IFEN.

Ministry of Ecology an Sustainable Development. (2003). Guide juridique de la prévention des risques majeurs. Collection Prévention des risques naturels. MEDD, France.

National Institute of Industrial Environment and Risks. (1999). Guide des méthodes d'évaluation des effets d'une explosion de gaz à l’air libre. Direction des Risques Accidentels Unité thématique Phénoménologie, INERIS.

National Institute of Industrial Environnement and Risks. (2001). Emission accidentelle d'une substance chimique dans l'atmosphère. INERIS

National Institute of Research and Security. (1998). Prévention du risque chimique. INRS Paris.

National Institute of Research and Security. (2001). Maîtrise des risques prévention et principe de précaution. INRS, Paris.

National Institute of Research and Security. (2001). Prévention des risques d'incendie et d'explosion de poussières de farine lors du stockage. INRS Paris.

Nationale Institute of Research and Security. (1981). Prévention et lutte contre le feu. INRS 1981.

SONATRACH. (2005). Santé, sécurité, environnement et développement durable Bulletin mensuel édité par la Cellule Communication Activité Aval. No. 1 juillet, SONATRACH. 